\title{
A Proposal on a Calculation Method to be applied by Geographical Comparison of Cancer Mortality
}

\author{
By
}

\author{
Mitsuo Segi, Ichiro Fukushima and Minoru Kurihara \\ (濒木三雄) (福島一郎) (漹 原 登) \\ From the Department of Public Health, Faculty of Medicine, \\ Tohoku University, Sendai ; Director: Prof. M. Segi
}

(Received for publication, November 6, 1953)

Heretofore, either crude or age-adjusted death rate has been used as the basic figures for geographical comparison of cancer mortality. Crude death rate is subject to influence of the age composition of the population, so that it is quite inappropriate for such a use as it is. In order to correct this defect, age-adjusted death rate has been widely used. However, while trying to compare the cancer mortality of various countries using age-adjusted death rates, we have been convinced that even these rates were not wholly adequate for an equitable comparison. The greatest defect of an age-adjusted death rate is that it is too closely dependent on the age composition of a standard population. For instance, when this rate is used in comparing the cancer mortality of several countries, different results may be obtained by taking the population of one country or another as standard, and sometimes even the order of the magnitude of the cancer mortality may be upset. That is to say, these figures lack absoluteness. In order to get rid of such a defect, some methods of corrections have been proposed, but none of these has proved wholly satisfactory.

In order to obtain numerical figures having a possibly absolute meaning, we have tried a system of computing the cancer mortality modifying the method applied to the preparation of abridged life tables. The method is to find out how many persons out of 100,000 born in a certain district have died from cancer and make geographical comparison according to this supposed number of deaths. As a matter of fact, we get at some different figures by the difference in the method of how to deal with those who have died of other causes except cancer. Hereunder, we will describe one of these methods.

Suppose that there is no cause of death but cancer. First of all, we must establish the cancer death rates by age group. Now, in a certain age group, if we express the number of population by $\mathrm{P}$, the actual number 


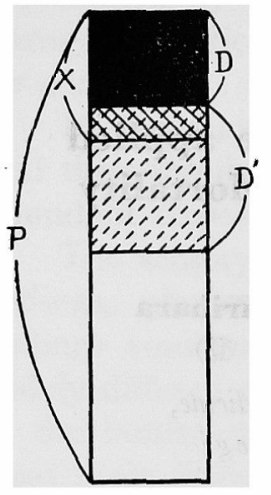

of cancer deaths by $\mathrm{D}$ and the actual number of deaths from other causes than cancer by $\mathrm{D}^{\prime}$, the death rate by cancer in general mean is $\mathrm{D} / \mathrm{P}$. If we assume that no death except from cancer occurs, it may be presumed that a part of the actual number of deaths from other causes must have died from cancer. Use $\mathbf{X}$ to denote the total number of cancer deaths, i.e., D plus this presumptive number of cancer deaths. If it is assumed that this presumptive number of cancer deaths included in $\mathrm{D}^{\prime}$ occurs in the proportion $\mathrm{X} / \mathrm{P}$, then $\mathrm{X}=\mathrm{D}+\mathrm{D}^{\prime} \cdot(\mathrm{X} / \mathrm{P})$, or $\mathrm{X} / \mathrm{P}=\mathrm{D} /\left(\mathrm{P}-\mathrm{D}^{\prime}\right)$. We computed this ratio for each age group.

Next we made computation after the method of calculating the data in abridged life tables. In Table I, "Mortality rate $\left({ }_{5} \mathrm{q}_{\mathrm{x}}\right)$ " means the ratio of the number of persons dying for age group $\mathrm{x} \sim \mathrm{x}+4$ to the total number of those living up to the age $\mathbf{x}$, "Number living $\left(1_{\mathbf{x}}\right)$ " means the number surviving to the exact age of $\mathrm{x}$, "Number dying $\left({ }_{5} \mathrm{~d}_{\mathrm{x}}\right)$ " means the number of deaths for age group $\mathrm{x} \sim \mathrm{x}+4$ and "Cumulative number dying $\left(c_{x+4}\right)$ " the total of deaths between the ages 0 and $x+4$. So,

$$
\begin{aligned}
& { }_{5} \mathrm{~d}_{\mathrm{x}}=1_{\mathrm{x} \cdot 5} \mathrm{q}_{\mathrm{x}} \\
& 1_{\mathrm{x}+5}=1_{\mathrm{x}}-{ }_{5} \mathrm{~d}_{\mathrm{x}} \\
& { }_{5} \mathrm{~d}_{\mathrm{x}+5}=1_{\mathrm{x}+5}{ }_{5} \mathrm{q}_{\mathrm{x}+5}=\left(1_{\mathrm{x}}-{ }_{5} \mathrm{~d}_{\mathrm{x}}\right) \cdot{ }_{5} \mathrm{q}_{\mathrm{x}+5}
\end{aligned}
$$

We begin the calculation on the assumption that the number living at the age $0\left(1_{0}\right)$ is 100,000 .

Thus, we can find the number dying for each age group if we know the mortality rate.

The cumulative number dying up to the age of $x+4$ years is calculated as follows:

$$
\mathrm{C}_{\mathrm{x}+4}={ }_{5} \mathrm{~d}_{0}+{ }_{5} \mathrm{~d}_{5}+{ }_{5} \mathrm{~d}_{10}+\ldots \ldots+{ }_{5} \mathrm{~d}_{\mathrm{x}-5}+{ }_{5} \mathrm{~d}_{\mathrm{x}}
$$

Applying the values of $\mathrm{X} / \mathrm{P}$ multiplied by 5 for ages $\mathrm{x} \sim(\mathrm{x}+4)$ years

TABLE I

\begin{tabular}{c|c|c|c|c}
\hline Age interval & Mortality rate & $\begin{array}{c}\text { Number living } \\
\mathrm{x} \sim(\mathrm{x}+4) \text { years }\end{array}$ & $\begin{array}{c}\text { Number dying } \\
{ }_{5} \mathrm{q}_{\mathbf{x}}\end{array}$ & $\begin{array}{c}\text { Cummulative } \\
\text { number dying } \\
\mathbf{c}_{\mathbf{x}+4}\end{array}$ \\
\hline $0 \sim 4$ & 0.000120 & 100,000 & ${ }^{\mathbf{x}} \mathrm{d}_{\mathbf{x}}$ & 12.0 \\
$5 \sim 9$ & 0.000040 & $99,988.0$ & 12.0 & 1.0 \\
$10 \sim 14$ & 0.000045 & $99,984.5$ & 4.5 & 16.0 \\
$\vdots \vdots$ & $\vdots$ & $\vdots$ & $\vdots$ & $\vdots$ \\
$80 \sim 84$ & 0.028340 & $84,134.1$ & $2,384.4$ & $\vdots$ \\
& & &
\end{tabular}


previously found out to ${ }_{5} \mathrm{q}_{\mathrm{x}}$, we have obtained the data given in Table I ${ }_{5} \mathrm{q}_{\mathrm{x}}$ in the abridged life table is not calculted using the five-fold value of death rate for ages $\mathrm{x} \sim(\mathrm{x}+4)$ as it is, but upon correcting it by a rather complicated adjustment. In this paper, however, for simplicity's sake, we have used the five-fold value of death rate by age group as it is).

Table II show the figures calculated by the above mentioned method illustrating the mortality from malignant neoplasm in Japan, England and Wales and U.S.A. in the year 1949. For reference, we have indicated the age-adjusted death rates standardized to the Japanese population. The figures in parentheses stand for the comparative indices with Japan (100) as basis.

TABLE II

\begin{tabular}{c|c|c}
\hline & $\begin{array}{c}\text { Cumulative number dying } \\
\text { up to the age 85 }\end{array}$ & $\begin{array}{c}\text { Age-adjusted } \\
\text { death rate }\end{array}$ \\
\hline Male: & $18,250(100)$ & $73.4(100)$ \\
Japan & $31,221(171.1)$ & $104.6(142.5)$ \\
England \& Wales & $28,095(153.9)$ & $91.4(124.5)$ \\
U.S.A. (White) & $21,056(115.4)$ & $89.4(121.8)$ \\
U.S.A. (Nonwhite) & $13,755(100)$ & $69.0(100)$ \\
\hline Female: & $22,974(167.0)$ & $91.9(133.2)$ \\
Japan & $22,915(166.6)$ & $96.6(140.0)$ \\
England \& Wales & $18,732(136.2)$ & $101.7(147.4)$ \\
U.S.A. (White) & &
\end{tabular}

It may be said that this method has a defect in that it involves the unnatural assumption that there is no cause of death other than cancer. Since, however, it is thus saved from being influenced by other causes of death, it is, we believe, the most appropriate for geographically comparing the status of cancer mortality. In this method, it is presumed that a part of those who are classified as died from other causes actually had died from cancer. But as in fact, cancer plays a major role as a cause of death over the other causes of death, we are afraid the values we have calculated are a little too high. It is necessary for this commputation to have the exact numbers of the population and deaths by age group. When the eldest age group is indicated somewhat as " above . . . years of age", we have no means to make computations; in such cases we can only find out the cumulative number dying up to the next lower age group. On the other hand, when we make such computations on cancer mortality by the site of cancer, the problem of how to treat those who died from cancers in other sites than the one in question will present itself. It we calculate the figures assuming that there is no death from cancers in other sites, the total of the figures thus calculated for each site will not add up to the figures computed for cancers in all sites in one. 
After all, the figures found out by this method will show how many persons out of 100,000 babies born simultaneously will die in the lapse of time from their birth to a certain year of age, under the assumption that cancer death rates by age group in a year will hold good in subsequent years too and that there is no death from other causes but cancer. Quite different from the age-adjusted death rate system, no standard population ever used in our method and the resultant values do not involve any external element except death from cancer. From this point of view, it can be called a method to insure absolute values indicating the status. of cancer mortality. 